\title{
Ovarian cancer risk in premenopausal and perimenopausal women treated with Tamoxifen: a case-control study
}

\author{
AJ Swerdlow*, and ME Jones' for the British Tamoxifen Second Cancer Study Group ${ }^{2}$ \\ 'Section of Epidemiology, Institute of Cancer Research, Sutton, Surrey SM2 5NG, UK
}

\begin{abstract}
As tamoxifen stimulates ovarian steroidogenesis in premenopausal women, induces ovulation and increases the incidence of benign ovarian cysts, there has been concern that it might also increase ovarian cancer risk in women treated premenopausally. In a national case-control study in Britain, treatment histories were collected for 158 cases of ovarian cancer after breast cancer diagnosed at ages under 55 years and 464 controls who had breast cancer at these ages without subsequent ovarian cancer. Risk of ovarian cancer was not raised for women overall who had taken tamoxifen (odds ratio $(O R)=0.9,95 \%$ confidence interval $(\mathrm{Cl}) 0.6-1.3$ ) or for those treated when premenopausal $(O R=1.0,95 \% \mathrm{Cl} 0.6-1.6)$ or perimenopausal $(\mathrm{OR}=0.7,95 \% \mathrm{Cl} 0.2-2.4)$. There was also no relation of risk to daily dose, duration or cumulative dose of tamoxifen, or time since last use. There was, however, a significantly raised risk in relation to non-hormonal chemotherapy. The results suggest that tamoxifen treatment of premenopausal or perimenopausal women does not materially affect ovarian cancer risk, but that non-hormonal chemotherapy might increase risk. British Journal of Cancer (2007) 96, 850-855. doi:I0.I038/sj.bjc.6603605 www.bjcancer.com
\end{abstract}

Published online 6 February 2007

(c) 2007 Cancer Research UK

Keywords: ovarian cancer; tamoxifen; breast cancer

Tamoxifen, a non-steroidal anti-oestrogen, has been used successfully in the treatment of breast cancer since the early 1970s, and, more recently, has been investigated as a prophylactic agent in women at high risk of breast cancer. In premenopausal women, however, tamoxifen induces ovulation (Messinis and Nillius, 1982), stimulates ovarian steroidogenesis (Jordan et al, 1991), causes ovarian enlargement (Gerhard and Runnebaum, 1979) and increases the incidence of benign ovarian cysts (Powles et al, 1994). There has therefore been concern that it might increase the risk of ovarian cancer in such women (Spicer et al, 1991). Studies of ovarian cancer risk after tamoxifen treatment have been entirely (Rutqvist et al, 1995) or largely (Cook et al, 1995; Curtis et al, 1996; Fisher et al, 1998; Early Breast Cancer Trialists' Collaborative Group, 2005) based on postmenopausal women, with small numbers, and without analyses for premenopausal women. We

*Correspondence: Professor AJ Swerdlow;

E-mail: anthony.swerdlow@icr.ac.uk

${ }^{2}$ The British Tamoxifen Second Cancer Study Group comprises: Anthony J Swerdlow DSc, Michael E Jones PhD; David H Brewster MD (Scottish Cancer Intelligence Unit); David Forman PhD (Northern \& Yorkshire Cancer Registry \& Information Service); Sara Godward PhD (East Anglian Cancer Intelligence Unit); Anthony Moran MB (North Western Cancer Registry); Gill Lawrence PhD (West Midlands Cancer Intelligence Unit); Henrik Møller PhD (Thames Cancer Registry); Monica Roche MBBS (Oxford Cancer Intelligence Unit); Paul Silcocks MSc (Trent Cancer Registry); John A Steward PhD (Welsh Cancer Intelligence \& Surveillance Unit); Julia Verne PhD (South \& West Intelligence Unit); Evelyn MI Williams MD (Merseyside \& Cheshire Cancer Registry).

Received II December 2006; revised 5 January 2007; accepted 5 January 2007; published online 6 February 2007 therefore conducted a national case-control study in Britain to investigate whether tamoxifen treatment of premenopausal women affects their risk of ovarian cancer.

\section{MATERIALS AND METHODS}

With the appropriate ethical approval, data were extracted from each of the population-based cancer registries in Britain except the Northern registry, on all women with breast cancer occurring from 1983 to 1996, or to the most recent year of available data, if earlier. The Northern registry, covering $5 \%$ of the population, was excluded because the requisite data were not available. The restriction to breast cancers incident since 1983 was because a pilot investigation had shown that tamoxifen use at premenopausal ages had been relatively uncommon before that year. The data extracted included information on second cancers. Subjects in the registry files were eligible as cases if they (i) had had a registered primary breast cancer diagnosed during $1983-1996$ below age 55 years, (ii) at that time had had no previous or concurrent cancer, (iii) had had a registered primary ovarian cancer diagnosed during 1988 1996, at least 3 months after incidence of the breast cancer, with no other second malignancy, except non-melanoma skin cancer or breast cancer, occurring in the intervening period.

The controls were women with breast cancer diagnosed during 1983-1996 below age 55, selected from the same computer files as the cases. Two controls were chosen per case, individually matched on (1) date of incidence of the primary breast cancer, within \pm 6 months, (2) age at incidence of the primary breast cancer, within \pm 6 months, (3) registry region of residence at diagnosis of the primary breast cancer, (4) survival without second cancer after breast cancer diagnosis for the same length of time as that from 
breast cancer diagnosis to ovarian cancer diagnosis in the matched case ('the index duration'). Additionally, it was required that controls (5) had not had an oophorectomy by the end of their index duration after diagnosis of breast cancer and (6) had casenotes that included the period up to the end of the index duration. As the last two criteria could not be determined from the cancer registry file, we examined the case-notes of potential controls chosen on criteria $(1-4)$, and if criterion (5) or (6) was not met (or the case-notes could not be found), a replacement control was chosen on criteria (1-4), with repetition as needed.

For each case and control, we extracted data from the hospital case-notes on demography, the general practitioner, tamoxifen treatment (start and stop dates, and dosage, for each period of treatment), other treatments of the first primary cancer, abdominal and pelvic radiotherapy before the first primary cancer, date of diagnosis of the first and second cancers and histological type of the ovarian cancer. Treatment histories for cases were included up to the date of diagnosis of the second cancer. For matched controls, they were included for the equivalent duration from diagnosis of the first primary (i.e. for the 'index duration'). For subjects for whom tamoxifen data in the hospital notes were incomplete, we contacted general practitioners to obtain more complete information.

In parallel with the ovarian cancer study, case-control studies of risks of several other cancers after breast cancer treatment were conducted, using the same procedures and data extraction forms. The controls from these studies who had not had an oophorectomy met the general criteria to be controls for the ovarian cancer cases, and we therefore used them as controls in the present analyses, to maximise power. To include these controls, we created matching strata for each of the critical variables (date and age at breast cancer diagnosis, index duration and region of the country), and assessed the effects of tamoxifen and other risk factors on ovarian cancer risk by calculation of stratum-matched odds ratios (ORs), as estimates of relative risks (and referred to as such below). Odds ratios (ORs), 95\% confidence intervals (CIs) for the ORs, and trend tests were calculated by conditional logistic regression (Breslow and Day, 1980). In addition, to check that the results were not biased by addition of these extra controls, we conducted matched reanalyses, by conditional logistic regression (Breslow and Day, 1980), confined to the controls originally collected to match the ovarian cancer cases. All statistical tests were two-sided.

Because cancer registry data do not include menopausal status, we included in the study all women diagnosed at ages under 55, and after we had extracted data from the case-notes we divided the subjects for analysis into (i) women known to be premenopausal, or presumed to be so because they were aged under 45 at diagnosis of breast cancer and of unstated menopausal status and (ii) women stated to be postmenopausal or perimenopausal (we have referred to these collectively in this study as perimenopausal, for simplicity, as even the postmenopausal subjects were generally close to the menopause (on average 4 years previously) because of the age range of the study), and (iii) women aged 45 and older of unstated menopausal status.

\section{RESULTS}

We identified 162 patients with ovarian cancer who met the study criteria and for whom full case-notes were found. We also identified 47 provisionally eligible case patients from cancer registry records whose case-notes could not be located or who had insufficient information for the study. Not all of these patients would have been eligible if their notes had been located. The 47 excluded case patients were similar to the patients with full casenotes with respect to age but slightly more likely to have been diagnosed early in the study period. Of the 162 patients with full case-notes available, at least one stratum-matched control patient was found for 158 subjects, who formed the study cases.

Full case-notes were available, and extracted, for 464 eligible controls in strata that contained any cases. We also identified 182 potential controls from cancer registry records whose full casenotes could not be found. Some of these 182 subjects would have been ineligible if the notes had been located and a record of oophorectomy found. These 182 subjects were similar to the 464 controls with available notes with regard to age and slightly more likely to have been diagnosed in the early years of the study.

Most cases and controls lived in England (Table 1). In $40 \%$ of the cases, breast cancer had been diagnosed below age 45 , and in $60 \%$ at ages $45-54$. Two-thirds of the cases and over half of the controls were known to have been premenopausal at breast cancer diagnosis (89 cases, 227 controls) or were probably so because they were aged below 45 years at breast cancer diagnosis and of unknown menopausal status (10 cases, 24 controls). Fifty-four percent of cases and $60 \%$ of controls had been treated with tamoxifen.

The OR for ovarian cancer after tamoxifen was $0.9(0.6-1.3)$ for the subjects overall (Table 2), $1.0(0.6-1.6)$ for those premenopausal according to the criteria described in the Materials and Methods, $0.9(0.5-1.6)$ for women explicitly stated to be premenopausal (not shown in the Table), and $0.7(0.2-2.4)$ for those perimenopausal (not shown in the Table). In analyses restricted to matched controls (see Materials and methods), the overall relative risk was $0.9(0.5-1.4)$ (not shown in the table). The risk in women who were premenopausal at breast cancer diagnosis and had not received ovarian ablation radiation or alkylating chemotherapy (i.e. breast cancer treatments that might cause premature menopause) was $0.9(0.5-1.6)$. There were too few germ-cell tumours (2) to analyse this distinctive group separately.

Ovarian cancer risk showed no relation to duration, average daily dose, cumulative dose, time since first use, or time since last use of tamoxifen, either for the subjects overall (Table 2), or for pre- or perimenopausal women separately. There were, however, significantly raised risks for tamoxifen users for whom information on dose, duration, or time since last treatment was unavailable.

Risk of ovarian cancer was not related to non-tamoxifen hormonal treatments (although few women had received such treatments), but was significantly raised in those who had been given non-hormonal chemotherapy (Table 3) and this remained true after adjustment for tamoxifen use $(\mathrm{OR}=1.8(1.1-2.9)$; not in table). The most frequently used non-hormonal chemotherapy was the cyclophosphamide, methotrexate, fluorouracil (CMF) regimen, for which ovarian cancer risk was similar to that for chemotherapy overall. The next most common non-hormonal chemotherapy was cyclophosphamide without methotrexate or fluorouracil. The number of cycles of CMF was known for less than half of subjects receiving this treatment and where known was almost always six, in cases and controls. Risk of ovarian cancer was not related to radiotherapy, which was generally to the breast, but occasionally was to the ovary for ablation; two cases and no controls had received such ablative radiotherapy at least 5 years ago (not in table).

Risk was not significantly related to smoking history, whether parous, or use of hormone replacement therapy (which was uncommon in this mainly premenopausal group), but increased significantly with increasing weight $(\mathrm{OR}=1.31(1.05-1.63)$ per $10 \mathrm{~kg}$ for all subjects; $1.51(1.11-2.04)$ per $10 \mathrm{~kg}$ for premenopausal subjects) (not shown in table).

\section{DISCUSSION}

Tamoxifen stimulates the ovary when used premenopausally, raising concern that it might increase the risk of ovarian cancer (Spicer et al, 1991). This concern is heightened because tamoxifen 
Table I Descriptive characteristics of study subjects

\begin{tabular}{|c|c|c|c|c|}
\hline Characteristic & \multicolumn{2}{|c|}{ Cases } & \multicolumn{2}{|c|}{ Controls } \\
\hline England & 133 & 84.2 & 390 & 84.1 \\
\hline Wales & 5 & 3.2 & 5 & 1.1 \\
\hline Scotland & 20 & 12.7 & 69 & 14.9 \\
\hline $45-49$ & 46 & 29.1 & 157 & 33.8 \\
\hline $50-54$ & 49 & 31.0 & 174 & 37.5 \\
\hline \multicolumn{5}{|l|}{ Year of diagnosis of breast cancer } \\
\hline $1983-84$ & 40 & 25.3 & 97 & 20.9 \\
\hline $1985-89$ & 86 & 54.4 & 251 & 54.1 \\
\hline $1990-94$ & 32 & 20.3 & 116 & 25.0 \\
\hline \multicolumn{5}{|c|}{ Menopausal status at diagnosis of breast cancer } \\
\hline Premenopausal & 102 & 64.6 & 260 & 56.0 \\
\hline Peri- or postmenopausal & 36 & 22.8 & 122 & 26.3 \\
\hline Unknown & 20 & 12.7 & 82 & 17.7 \\
\hline \multicolumn{5}{|l|}{ Treatment of breast cancer ${ }^{a}$} \\
\hline Radiotherapy & 99 & 62.7 & 290 & 62.5 \\
\hline Non-hormonal chemotherapy & 33 & 20.9 & 66 & 14.2 \\
\hline Tamoxifen & 85 & 53.8 & 279 & 60.1 \\
\hline Other hormonal therapies & 6 & 3.8 & 17 & 3.7 \\
\hline Total subjects & 158 & 100.0 & 464 & 100.0 \\
\hline
\end{tabular}

${ }^{a}$ At least 3 months before date of diagnosis of ovarian cancer (or among controls, at least 3 months before index date).

is as effective as clomiphene in inducing ovulation (Messinis and Nillius, 1982), and clomiphene has been associated with raised ovarian cancer risk in some studies (Rossing et al, 1994; Brinton et al, 2004), although not others (Ness et al, 2002).

Ovarian cancer after breast cancer is not common, and previous studies have been based on small numbers. One case-control study has been published of ovarian cancer risk after tamoxifen treatment, based on only 34 cases, of whom seven were premenopausal. This found no increase in ovarian cancer, or relation of risk to duration of treatment, but the CIs were wide (Cook et al, 1995). Cohort studies of women aged 50 years or above (Curtis et al, 1996) or postmenopausal women (Rutqvist et al, 1995) treated with tamoxifen did not show increased ovarian cancer risk, but were based on small numbers of cancers in treated women (20 and 22, respectively); the same was true for raloxifene treatment (Neven et al, 2002). Two large follow-up studies of trials patients, mainly aged 50 and above, did not analyse ovarian cancer risk, but found similar numbers of ovarian cancers in the similarsized tamoxifen (11 cases) and placebo (10 cases) groups (Fisher et al, 1998) or tamoxifen (25 cases) and control (22 cases) groups (Early Breast Cancer Trialists' Collaborative Group, 2005). A cancer registry-based study that analysed hormonal treatment overall, with incomplete follow-up and no data on the particular drug or duration of treatment (Newcomb et al, 1999), found ovarian cancer risk was not raised either in the first 5 years after breast cancer or subsequently. The relationship between risk and daily dose of tamoxifen does not appear to have been examined.

Our data show no effect of tamoxifen on risk of ovarian cancer overall, no effect of dose or duration, and no relation to duration since last use. The CIs for the dose and duration relations exclude all but modest effects. Subanalyses by menopausal status, identifying this as so-stated or based on age, did not show raised risk for either premenopausal or perimenopausal women. The only significant relationship with tamoxifen use was for the category of unknown dose and duration of use. This is most unlikely to represent a real effect, and is probably an artefact of the difficulty of gaining detailed data for patients who have died several years ago, who tend to be cases rather than controls. In our case-control study of endometrial cancer risk after tamoxifen in the same population (Swerdlow and Jones, 2005), for which there is a wellestablished effect of tamoxifen on risk, cancer risks in users with an unknown dose and duration of treatment were similar to those in patients with known intermediate values of these variables. As the unknown categories in the present study occurred in less than $10 \%$ of all subjects and under $15 \%$ of users, the effects on the results for the known categories should have been minimal if any.

In principle, any tamoxifen-related risks of ovarian cancer might be confounded by genetic factors, if breast cancers occurring in patients with BRCA1, BRCA2 or PeutzJeghers syndrome (which predispose to ovarian as well as breast cancer) were more, or less, likely to be treated with tamoxifen than other breast cancers. A greater proportion (above 90\%) of tumours in BRCA1 patients are oestrogen receptor-negative than occurs in other breast cancers at the same ages (Lakhani et al, 2005), so there could be a bias towards lower tamoxifen use in ovarian cancer patients than controls, if choice of breast cancer therapy was influenced by oestrogen receptor status. Over the study period, however, it is unlikely that more than a quarter of breast cancers nationally were tested for oestrogen receptor status (Dowsett $M$, pers comm), and we estimate that at most a third of ovarian cancers after breast 
Table 2 Risk of ovarian cancer in relation to tamoxifen treatment, duration, daily dose, cumulative dose and time since last use, all subjects, and premenopausal subjects separately ${ }^{a}$

\begin{tabular}{|c|c|c|c|c|c|c|c|c|}
\hline Tamoxifen treatment & \multicolumn{4}{|c|}{ All subjects } & & & & \\
\hline \multicolumn{9}{|l|}{ Any tamoxifen treatment } \\
\hline No & 73 & 46.2 & 185 & 39.9 & 1.0 & & 1.0 & \\
\hline Yes & 85 & 53.8 & 279 & 60.1 & 1.0 & $(0.6-1.6)$ & 0.9 & $(0.6-1.3)$ \\
\hline \multicolumn{9}{|l|}{ Duration of treatment (years) } \\
\hline Not used & 73 & 46.2 & 185 & 39.9 & 1.0 & & 1.0 & \\
\hline$<2$ & 32 & 20.3 & 128 & 27.6 & 0.8 & $(0.4-1.5)$ & 0.7 & $(0.4-1.1)$ \\
\hline $2-4$ & 19 & 12.0 & 92 & 19.8 & 0.6 & $(0.3-1.4)$ & 0.5 & $(0.3-1.0)^{b}$ \\
\hline $5-12$ & 16 & 10.1 & 44 & 9.5 & 0.8 & $(0.3-2.3)$ & 1.2 & $(0.6-2.5)$ \\
\hline \multirow[t]{2}{*}{ Used, duration unknown } & 18 & 11.4 & 15 & 3.2 & 5.6 & $(1.9-16.5)^{c}$ & 3.2 & $(1.5-6.7)^{c}$ \\
\hline & & & & & \multicolumn{2}{|c|}{ Heterogeneity : $P=0.64$} & \multicolumn{2}{|c|}{ Heterogeneity: $P=0.13$} \\
\hline Trend OR/year $^{d}$ & & & & & 0.93 & $(0.81-1.07)$ & 0.99 & $(0.90-1.09)$ \\
\hline \multicolumn{9}{|l|}{ Average daily dose $(m g)^{\mathrm{e}}$} \\
\hline \multirow[t]{2}{*}{ Used, dose unknown } & 17 & 10.8 & 23 & 5.0 & \multirow{2}{*}{\multicolumn{2}{|c|}{ Heterogeneity : $P=0.79$}} & 2.0 & $(1.0-4.1)$ \\
\hline & & & & & & & \multicolumn{2}{|c|}{ Heterogeneity: $P=0.40$} \\
\hline Trend OR/IO mg per day ${ }^{d}$ & & & & & 0.95 & $(0.79-1.15)$ & 0.91 & $(0.78-1.06)$ \\
\hline \multicolumn{9}{|l|}{ Cumulative dose (mg) } \\
\hline Not used & 73 & 46.2 & 185 & 39.9 & 1.0 & & 1.0 & \\
\hline$<7500$ & 17 & 10.8 & 56 & 12.1 & 1.3 & $(0.6-2.8)$ & 0.9 & $(0.5-1.7)$ \\
\hline $7500-14999$ & 11 & 7.0 & 54 & 11.6 & 0.6 & $(0.2-1.4)$ & 0.5 & $(0.3-1.1)$ \\
\hline $15000-29999$ & 13 & 8.2 & 62 & 13.4 & 0.6 & $(0.2-1.4)$ & 0.6 & $(0.3-1.1)$ \\
\hline $30000-59999$ & 13 & 8.2 & 59 & 12.7 & 0.5 & $(0.2-1.4)$ & 0.6 & $(0.3-1.3)$ \\
\hline$\geqslant 60000$ & 8 & 5.1 & 18 & 3.9 & 0.8 & $(0.2-2.8)$ & 1.3 & $(0.5-3.3)$ \\
\hline \multirow{2}{*}{ Used, dose unknown } & 23 & 14.6 & 30 & 6.5 & 3.5 & $(1.5-8.1)^{c}$ & 2.1 & $(1.1-3.8)^{b}$ \\
\hline & & & & & \multicolumn{2}{|c|}{ Heterogeneity $P=0.34$} & \multicolumn{2}{|c|}{ Heterogeneity: $P=0.30$} \\
\hline Time since last known use & & & & & & & & \\
\hline Not used & 73 & 46.2 & 185 & 39.9 & 1.0 & & 1.0 & \\
\hline Still on or $<$ I year & 57 & 36.1 & 233 & 50.2 & 0.7 & $(0.4-1.2)$ & 0.7 & $(0.5-1.1)$ \\
\hline $1-2$ years & 7 & 4.4 & 20 & 4.3 & 1.0 & $(0.3-4.2)$ & 1.1 & $(0.4-2.7)$ \\
\hline $3-8$ years & 5 & 3.2 & 14 & 3.0 & 1.7 & $(0.4-6.8)$ & 0.9 & $(0.3-2.6)$ \\
\hline Used, time unknown & 16 & 10.1 & 12 & 2.6 & 6.5 & $(2.0-20.9)^{c}$ & 3.5 & $(1.6-8.0)^{c}$ \\
\hline & & & & & & $P=0.34$ & & $P=0.33$ \\
\hline Trend OR/year $^{f}$ & & & & & 1.24 & $(0.88-1.74)$ & 1.09 & $(0.87-1.36)$ \\
\hline
\end{tabular}

${ }^{a}$ Unless otherwise indicated, all tamoxifen-related exposures are those at least 3 months before the index date. ${ }^{b} P<0.05 .{ }^{c} P<0.01$. ${ }^{d}$ Trend and heterogeneity tests exclude missing value group, and include non-users as zero level. ${ }^{e}$ Averaged over period known to be on tamoxifen: $20=10-24 \mathrm{mg} / \mathrm{day}$ but mostly $20 \mathrm{mg} / \mathrm{day} ; 40=25-42 \mathrm{mg} / \mathrm{day}$ but mostly $40 \mathrm{mg} /$ day. ${ }^{\mathrm{f}}$ Trend excludes not used and missing value groups.

cancer at the study ages might be in BRCA1 carriers (Ford, 2000), so the overall effect on the ovarian cancer relative risk in relation to tamoxifen in our data should have been small.

Although risks of ovarian cancer were not related to nontamoxifen hormonal treatments for breast cancer or to radiotherapy, there was a significantly raised risk in relation to chemotherapy. On the basis of small numbers we could not attribute this to a specific treatment, risks being similar for CMF as for other (heterogeneous) non-hormonal chemotherapy. Published data on ovarian cancer risks after chemotherapy for breast cancer are based on small numbers of cases, but in an Italian cohort there was a significant excess of ovarian cancer after chemotherapy for breast cancer, most of which was CMF (Rubagotti et al, 1996), and in an international pooled trials analysis there were more ovarian cancers after polychemotherapy (38) than in a similar number of breast cancer patients not so treated (28) (Early Breast Cancer Trialists' Collaborative Group, 2005). Breast cancer chemotherapy includes several agents that are known carcinogens in humans and/or animals (Tomatis et al, 1990), although it is unknown if any can cause ovarian cancer specifically. The relation found with 
Table 3 Risk of ovarian cancer in relation to non-tamoxifen breast cancer treatment

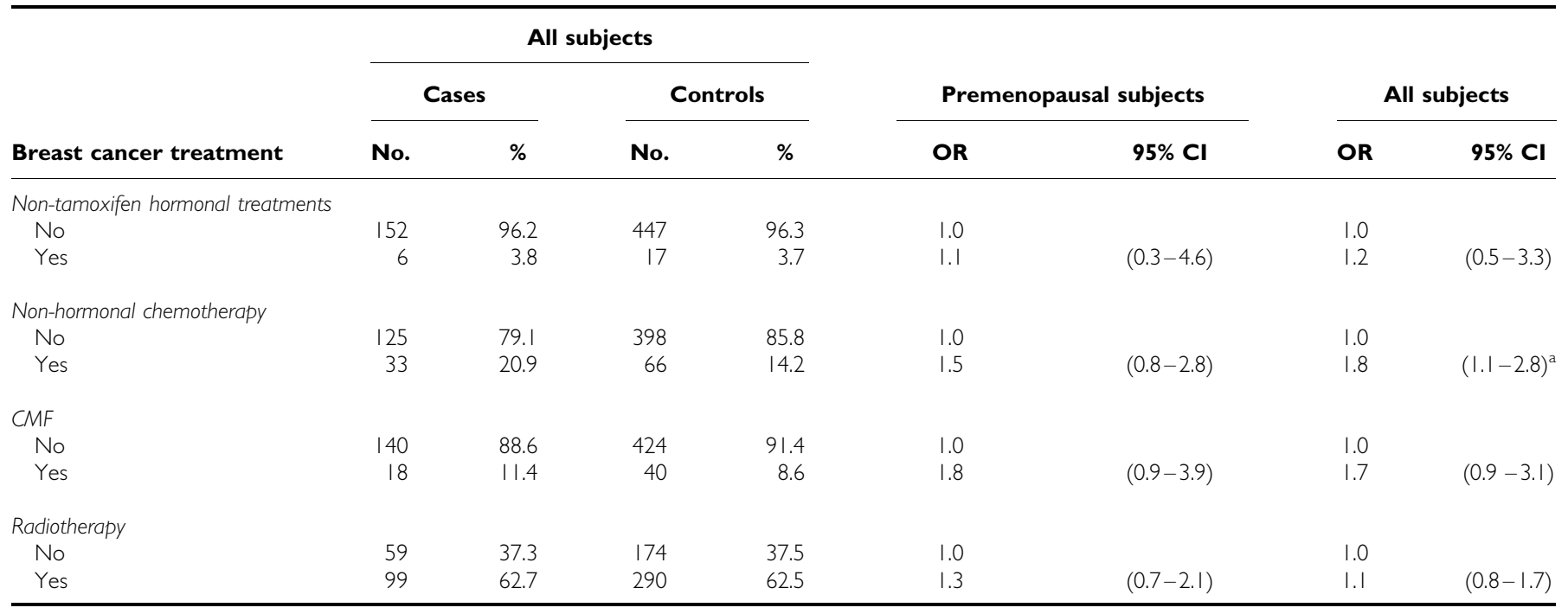

$\mathrm{CMF}=$ cyclophosphamide, methotrexate, fluorouracil. ${ }^{\mathrm{a}} P<0.05$.

chemotherapy was not our original study hypothesis, and as a consequence detailed data had not been collected to explore it further. Our results suggest, however, that tamoxifen treatment of premenopausal or perimenopausal women does not materially affect ovarian cancer risk, but that non-hormonal chemotherapy might do so.

\section{ACKNOWLEDGEMENTS}

We thank the Medical Research Council for funding, the staff of the cancer registries and in particular Dr T Davies, Mrs M Page,
Ms C Chester, Ms J Littler, Ms J Harvey, Ms J Evans, Ms J Harrison, Ms P Allgood, Dr D Etherington, Ms J Flaherty, Dr J Bell, Ms J Nicholas, Ms C Johnson, Mr A Waterhouse, Ms S Reynolds, Ms J Andrews, Mrs S Cook, Ms S Hall, Dr A Teale, Dr L Somervaille, Mrs J Stephenson, Ms A Ramsay, Ms C Storer, and nurses from the Aetiological Epidemiology Team, for facilitation and data extraction; hospital and primary care clinicians and medical records staff throughout Britain for help in obtaining data; Ms B Peachey and Mrs H Nguyen for data entry; Professor M Dowsett, Professor N Rahman and Professor J Yarnold for advice and Mrs M Snigorska for secretarial help.

\section{REFERENCES}

Breslow NE, Day NE (1980) Statistical Methods in Cancer Research. Volume 1-The Analysis of Case-Control Studies IARC Scientific Publications No. 32 Lyon: International Agency for Research on Cancer

Brinton LA, Lamb EJ, Moghissi KS, Scoccia B, Althuis MD, Mabie JE, Westhoff CL (2004) Ovarian cancer risk after the use of ovulationstimulating drugs. Obstet Gynecol 103: 1194-1203

Cook LS, Weiss NS, Schwartz SM, White E, McKnight B, Moore DE, Daling JR (1995) Population-based study of tamoxifen therapy and subsequent ovarian, endometrial, and breast cancers. J Natl Cancer Inst 87: $1359-1364$

Curtis RE, Boice Jr JD, Shriner DA, Hankey BF, Fraumeni Jr JF (1996) Second cancers after adjuvant tamoxifen therapy for breast cancer. J Natl Cancer Inst 88: 832-834

Early Breast Cancer Trialists' Collaborative Group (2005) Effects of chemotherapy and hormonal therapy for early breast cancer on recurrence and 15-year survival: an overview of the randomised trials. Lancet 365: $1687-1717$

Fisher B, Constantino JP, Wickerham DL, Redmond CK, Kavanah M, Cronin WM, Vogel V, Robidoux A, Dimitrov N, Atkins J, Daly M, Wieand S, Tan-Chiu E, Ford L, Wolmark N, other National Surgical Adjuvant Breast and Bowel Project Investigators (1998) Tamoxifen for prevention of breast cancer: report of the national surgical adjuvant breast and bowel project P-1 study. J Natl Cancer Inst 90: 1371- 1388

Ford D (2000) Genetic epidemiology of breast ovarian cancer. Doctor of Philosophy Thesis. London: The Institute of Cancer Research, University of London

Gerhard I, Runnebaum B (1979) Comparison between tamoxifen and clomiphene therapy in women with anovulation. Arch Gynecol 227: $279-288$

Jordan VC, Fritz NF, Langan-Fahey S, Thompson M, Tormey DC (1991) Alteration of endocrine parameters in premenopausal women with breast cancer during long-term adjuvant therapy with tamoxifen as the single agent. J Natl Cancer Inst 83: 1488-1491

Lakhani SR, Reis-Filho JS, Fulford L, Penault-Llorca F, van der Vijver M, Parry S, Bishop T, Benitez J, Rivas C, Bignon Y-J, Chang-Claude J, Hamann U, Cornelisse CJ, Devilee P, Beckmann MW, Nestle-Krämling C, Daly PA, Haites N, Varley J, Lalloo F, Evans G, Maugard C, MeijersHeijboer H, Klijn JG, Olah E, Gusterson BA, Pilotti S, Radice P, Scherneck S, Sobol H, Jacquemier J, Wagner T, Peto J, Stratton MR, McGuffog L, Easton DF, and the Breast Cancer Linkage Consortium (2005) Prediction of BRCA1 status in patients with breast cancer using estrogen receptor and basal phenotype. Clin Cancer Res 11: 5175-5180

Messinis IE, Nillius SJ (1982) Comparison between tamoxifen and clomiphene for induction of ovulation. Acta Obstet Gynecol Scand 61: 377-379

Ness RB, Cramer DW, Goodman MT, Kjaer SK, Mallin K, Mosgaard BJ, Purdie DM, Risch HA, Vergona R, Wu AH (2002) Infertility, fertility drugs, and ovarian cancer: a pooled analysis of case-control studies. Am J Epidemiol 155: 217-224

Neven P, Goldstein SR, Ciaccia AV, Zhou L, Silfen SL, Muram D (2002) The effect of raloxifene on the incidence of ovarian cancer in postmenopausal women. Gynecol Oncol 85: 388-390

Newcomb PA, Solomon C, White E (1999) Tamoxifen and risk of large bowel cancer in women with breast cancer. Breast Cancer Res Treat 53: $271-277$

Powles TJ, Jones AL, Ashley SE, O'Brien MER, Tidy VA, Treleavan J, Cosgrove D, Nash AG, Sacks N, Baum M, McKinna JA, Davey JB (1994) The Royal Marsden Hospital pilot tamoxifen chemoprevention trial. Breast Cancer Res Treat 31: 73-82 
Rossing MA, Daling JR, Weiss NS, Moore DE, Self SG (1994) Ovarian tumors in a cohort of infertile women. $N$ Engl J Med 331: 771-776

Rubagotti A, Perrotta A, Casella C, Boccardo F (1996) Risk of new primaries after chemotherapy and/or tamoxifen treatment for early breast cancer. Ann Oncol 7: 239-244

Rutqvist LE, Johansson H, Signomklao T, Johansson U, Fornander T, Wilking N, for the Stockholm Breast Cancer Study Group (1995) Adjuvant tamoxifen therapy for early stage breast cancer and second primary malignancies. J Natl Cancer Inst 87: 645-651
Spicer DV, Pike MC, Henderson BE (1991) Ovarian cancer and long-term tamoxifen in premenopausal women. Lancet 337: 1414

Swerdlow AJ, Jones ME, for the British tamoxifen Second Cancer Study Group. (2005) Tamoxifen treatment for breast cancer and risk of endometrial cancer: a case - control study. J Natl Cancer Inst 97: 375 - 384

Tomatis L, Aitio A, Day NE, Heseltine E, Kaldor J, Miller AB, Parkin DM, Riboli E (eds) (1990) Cancer: Causes, occurrence and control. IARC Scientific Publications, No. 100 Lyon: International Agency for Research on Cancer 